\title{
Some Strategies for Dealing with English Vocabulary in Reading
}

\author{
Yanhong Zhang \\ School of Humanities \\ Yantai Nanshan University \\ Yantai, Shandong, China 265713
}

\begin{abstract}
English is one of the most important languages in the world. It is important because of its worldwide use. More and more people in the world choose English as a foreign language for the purpose of profession, science and international communication. For English learners, Reading is one of the basic techniques in English study and meanwhile vocabulary is one key aspect in reading. During the reading process, we usually come across many new words. As an international language in this society, English has about one million English words in all. You can see English words almost every where, even in some non-English-spoken countries. Therefore, how to deal with the new words in reading process becomes a crucial issue for a foreign leaner. Good readers can use several techniques to deal with the problem to make their reading more effective. In this paper, some strategies and skills such as, scanning, guessing the meaning of the unknown words from word-structure and context and so on are introduced.
\end{abstract}

Keywords-scanning or neglect; word-structure; context; differences

\section{INTRODUCTION}

With the development of globalization, English reading is becoming more and more popular. No matter what purpose we have, such as, finding materials, getting information or chatting on line, we will encounter some new words. Considering the four aspects of English - reading, writing, speaking and listening, we do more reading. Therefore, mastering how to deal with unfamiliar words in reading will help us get more information from an article as fast as possible. A lot of specialists and scholars have studied the reading skills, strategies and how to deal with the new words when we are reading. Here, this paper emphasizes on how to deal with the new words in our reading.

\section{SCANNING OR NEGLECT}

Scanning is a way of finding out specific information quickly but not carefully and without having to read word by word. As we all know, words are the building blocks of reading. During the process of reading, we readers will come across new words, some of them, such as the people's name, place or even some proper names, etc, do not affect us during reading and then we can let them be-in other words, we can neglect the new words we meet. We just scan the needed information in the article quickly and without reading word by word or phrase by phrase. [R1]

\section{GUESSING WORD'S MEANING THROUGH WORD- STRUCTURE}

Some of the new words do not affect us during reading and then we ignore them. But when we come to a key word, what should we do? There is no doubt that we need to find out the meaning of the word, of course, we have certainly learned how to refer to a dictionary to help us find the exact meaning of words and perhaps the dictionary gives us additional information. But in my opinion, it is not always a good way using a dictionary all the way and in most cases it is not convenient. Otherwise, it not only wastes our time and energy, but also slowdown reading speed. Without a dictionary we still may know the meaning of the words by guessing through the following ways.

\section{A. Word Analysis}

We know that a word is the combination of form and meaning. In English many words are built on roots and affixes of Latin or Greek. Analyzing how they can be combined to make words, we will be able to enlarge our vocabulary and become a better reader. In word analysis, we may break down the unknown words into three parts, the beginning is prefix, the middle is root, and the end is suffix. Here is an example:

$$
\begin{array}{lll}
\text { Prefix } & \text { root } & \text { suffix } \\
\text { per sist tence }
\end{array}
$$

Roots and affixes are the small units that can be combined in various ways to make a variety of words. Furthermore, roots and affixes are constant in meaning. For example, the word element "tri" always means "three" and the word element "able" always means "capable". Therefore, when we learn some of these elements, we enlarge our vocabulary and it is also very skillful for us to guess the meaning of the words.

1) Prefix: The majority of prefixes are characterized by their non-class changing nature. Their chief function is to change meanings of the stems. Accordingly, the specialists classify prefixes on a semantic basis into nine groups.

a) Negative prfixes: A-, dis-, in-(it, ir- im-), non-, une.g. amoral (non-moral), apolitical( not political), disloyal(not 
loyal), disobey(not obey), injustice (without justice), illegal (not legal), irresistible (not to be resisted), immature (not mature), non-smoker (not a smoker), non-classical (not classical), unfair (not fair), unwilling(not willing).Of this group, un- is by far the most productive and can usually replace in- or dis- with adjectives for actual use as in replaceable, unmovable for irreplaceable and immovable.[R2]

b) Reversal Prefixes: De-, dis-, un-, e.g. decentralize(give greater power for self-government), decompose(separate into parts), disunite(become separate), disallow(refuse to allow ), unhorse(cause to fall from a horse ) unwrap(open).The prefixes of this group can all be found in previous class. The reason for their separation lies in the meaning.

c) Pejorative Prefixes: Mal-, mis-, pseudo-, e.g. maltreat (treat badly) malpractice (wrong doing), misconduct (bad behavior), mistrust(not to trust ); pseudo-friend(false friend) pseudo-science (false science). [R3]

d) Prefixes of degree or size: Arch-, extra-, hyper-, macro-, mini-, out-, over-, sub-, super-, sur-, ultra-, under-, e.g. archbishop(a priest in charge of bishops in a large area), extra-strong(very strong), hyperactive(extremely active), macrocosm(the universe), microcomputer(very small computer), mini-election(small-scale election), outlive(live longer than),overweight(weighing more than normal), subheading (secondary heading) super-freeze (freeze to a very low temperature), surtax(tax too much), ultra-conservative (extremely conservative) underdeveloped (less developed). [R4]

e) Prefixes of orientation and attitude: Anti- ,contracounter- ,pro- e.g. anti-nuclear, anti-government, contra-flow (the arrangement for the traffic to go on both directions on one side of the road ) pro-democracy (supporting democracy). [R5]

f) Locative Prefixes: Extra-, fore- , inter-, intra- , tele,trans-, e.g. extraordinary (more than ordinary), extramarital (outside marriage); forehead, forearm, inter-city (between cities), inter personal (concerning relations between people), intra-party (within the party) telecommunication by telephone, radio, television, etc.), trans-world (across the world ), transcontinental (across the continent). [R6]

g) Prefixes of time and order: Ex-, fore- ,post- pre- ,ree.g. ex-professor (former professor), ex-student (former student), foretell(tell before happening), foreknowledge (knowledge before happening), post-election (after election),pre-prepared(prepared before hand ), reconsider (consider again). [R7]

h) Number Prefixes: Bi-,multi-(poly-),semi-(hemi-), tri-, uni- (mono-), e.g. bicycle, bilingual (concerning two languages), multi-purpose (more than one purpose), polysyllable(more than one syllable), semi-naked(half naked ); hemisphere (a half of the earth on either side of equator ). tricycle (a vehicle with three wheels ), uniform (not different). Monorail (one rail). [R8] i) Miscellaneous Prefixes: Auto-, neo-, pan-, vice-, e.g. autobiography (biography written by oneself), neo- nazi (new Nazi), pan-European (the whole of Europe), viceChairman (deputy chairman). [R9]

2) Suffix: suffixes have their primary function of changing the grammatical function of stem. In other words, they mainly change the word class. Therefore, we shall group suffixes on a grammatical basis into noun suffixes, verb suffixes, adjective suffixes, etc. Here is a partial list of common suffixes.

a) Noun suffixes: The suffixes of this group are added to roots to produce nouns, such as ,-eer, -er, -ess, -ette, -let, age ,-dom, -ery, -hood, -ing, -ism,-ship, -ant, -ent, -ation, anee (-ence), -ment, e.g. profiteer (person who makes unfairly large profits), hostess (female host), priestess (female priest),Booklet (small book), Gangster (member of the gang), songster (skilled singer), officialdom (officials as a group), adulthood (condition of being an adult), terrorism (the use of violence to obtain political demands), friendship, informant(one who gives information to police, etc), respondent(one who depends on someone else for food clothing etc.).

b) Verb Suffixes: -ate, -en, -fy , -ize (-ise), e.g. originate (have...as origin), solidify (make...solid), beautify (make more beautiful).

In modern English, there are some seemingly productive vogue affixes like -ink (a person who becomes devoted to or a member of), which gives birth to quite a few words such as folkink (one fond of folk music), peacenik (devotee to peace ), jazznik (jazz fan ), protestnik (one who protests against something.)

c) Adjective Suffixes:-ed, -ful, -ish, -less, -like, -ly, -y, e.g. wooded (covered with trees) successful (achieving your aims or what was intended), foolish (actions or behavior not showing good sense or judgments ), dreamlike (as if existing or happening in a dream), friendly (behaving in a kind and pleasant way because you like somebody or want to help them), bloody(involving a lot of violence and killing).

It is not always easy to figure out the exact meanings for words from prefixes, suffixes and roots. But learning these word parts can help you acquire at least some hint of the meanings of many words without looking them up in a dictionary. If we are familiar with the word analyses and master the meaning and usage of these elements, we can guess the meaning of the words quickly and correctly.

\section{B. Compound Words}

Sometimes, readers will come across some words or groups of words which "go together" on account of their logical connections such as: grass-green, black-board, schoolstudent, hit-ball, swimming-pool, baby-sitter, alarm-clock, etc. These compound words also can be guessed by the basic knowledge of simple words. 


\section{GUESSING THE MEANING OF THE UnKNOWN WORDS FROM CONTEXT CLUES [R10]}

As most words have more than one meaning, it is often impossible to tell the meaning of a word before it is used in a context. Context is very important for the understanding of word-meaning because the meaning is influenced immediately by the linguistic context, and in many cases by the whole speech situation as well .when a writer or speaker uses a word, she/he makes it "mean just what he chooses it to mean----neither more or less". Without context there is no way to determine the very sense of the word that the speaker intends to convey, whereas with context there is generally no danger of misinterpretation for meaning lives in context and context defines meaning. We cannot learn all the meanings of all the words, but when we develop skills at using context clues, we will be able to figure out meanings for many words as we need. Using context clues is another way for readers to add to our vocabulary and become more effective readers.

Writers use at least eight kinds of context clues: definition, experience, example, summary, synonym or restatement, typography, comparison and/or contrast as well as word structure. As readers, we need to know how the clues are used.

\section{A. Definition Clues}

Often we notice that the author gives formal definition right after a new term. Example:

Perhaps the most startling theory to come out of kinesics, the study of body movement, was suggested by professor Birdwhistell.

Analysis: Maybe we don't know the word kinesics, but from the definition of the follow sentence, we can know that kinesics is a subject studied in school or college. [R11]

\section{B. Experience Clues}

People have both direct experiences and indirect experiences. Indirect experiences are experiences through reading, watching television or movies. These are all learning experiences that provide clues to word meaning. Because we readers know it from our own experiences, we have a context to follow. For example, we have knowledge of the chronometer and geography, customs and habits, faith, political, structures and social regime, etc. of some countries, which can help us understand the articles deeply and improve our ability of inferring or guessing the meaning of new words.

\section{Example:}

When my pineapple plant blooms, it develops a colorful inflorescence, which lose its flowers and turns into a fruit.

Using experience as context clue: Although we readers may not know the meaning of the word "inflorescence", we can tell from the sentence that an "inflorescence" is something that develops or appears on a plant, "lose its flowers and turns into a fruit", probably we have never grown a pineapple plant, but our experience tells us this plant ought to be something like other fruit-bearing plants. The experience indicates that they develop flowers or blossoms that fall away and are replace by fruit. Therefore, by using our experience as a clue, we can guess that the word "inflorescence" means "blossom".

Experience is especially essential if the reading material is on technique or science or other professional fields. In this case, the knowledge structure beyond the language will greatly contribute to the comprehension of the material. It is noticed that sometimes we understand the linguistic information, but this understanding is superficial, and deep understanding will more or less depend on whether we have relevant information on this subject.

\section{Explanation through Example}

In order to clarify an important concept or make an abstract concept clear, the author usually adopts examples to make readers understand the concept in detail. The examples in context are just the clues for the readers to follow or guess the meaning of new words.

\section{Examples:}

- Many United Nations employees are polyglot. Ms Mary, for example, speaks five languages.

Analysis: In this sentence, we may not know the exact meaning of the word "polyglot", but from the explanation and example, we cangues that this word mean "a person who can speaks many languages".

- The soldiers used all the weapons they had. For example, they used bayonets and muskets.

Analysis: Bayonets and muskets are examples of weapons and "weapons" are used in fighting. Therefore, "bayonets" and "muskets" are used in fighting.

\section{Explanation through Summary}

Sometimes we encounter an unknown word but we can figure out the meaning because the context supplies us with a summary; that is the author gives readers several pieces of information in words we do understand. Then we can tell from the context that the unfamiliar word summarizes or ties together those statements. The word that is being explained, the unknown word, may come either before or after the information of summaries.

\section{Example:}

- Marie was a comely girl. She had short, curly hair and dig brown eyes; she was tall, slim and had perfect pasture.

Analysis: The sentence following the word "comely" describes Marie and contains words that indicate someone who has good qualities. Therefore, the clues indicate that "comely" means "attractive-looking" or "pretty".

\section{E. Synonym or Restatement Clues}

A synonym, which is a word that means nearly the same as another word, is one of type of context clue that helps readers to determine the meaning of unfamiliar words. Sometimes an author uses a word unfamiliar to us also writes a synonym for emphasis or to take a meaning of unknown word. This type of 
clue is sometimes called a "restatement" clue, because the synonym restates the idea.

Examples:

- In some isolated regions in the word, people continue to live as they did years ago. In these areas, which are separated from the rest country, there does not seem to be a great concern with conserving natural resources.

Analysis:

The word "isolated" means "separated from" because the meaning of "isolated" was repeated in the second sentence.

- The candidate was surrounded by his followers, his adherents.

\section{Analysis:}

The first part of the sentence uses familiar words, the unfamiliar word "adherents" appears after the comma therefore the word that gives the meaning for it is before the comma. The clue shows the meaning of "adherents" is followers".

\section{F. Comparison and/or Contrast Clues}

Comparison means similarity, contrast means difference. The words are usually used together because contrast can exist only where there are some elements of similarity. When a comparison clue is used, we readers can understand the meaning of unknown word by deterring how it is similar to a word already known. A contrast clue gives the readers information about how the unknown word differs from an idea expressed in familiar words.

Readers guess the meaning of words through antonyms. In the course of contrast, the author uses some antonyms to make the characteristics of different things more outstanding; as a result, we are able to infer the meaning of new words from our familiar words through the logic relation in the context or the description for the contrast of those different things or phenomena." In addition, when showing this kind of contrast, the author will commonly use some symbol words such as "but", "yet", "however", "despite", "though", "rather than", "unlike", "not", "in spite of", "in contrast", "though" and the co-ordinates linked by "while" etc to figure out that some word is antonym of another one. Readers can understand or guess the meaning of new words just through these antonyms. [R12]

\section{Example:}

"Bill was good at art, music, and photography, and his brother was even more versatile."

The clue: If Bill is described as being good at art, music and photography, he is obviously good at doing many thing, Because his brother is described as even more versatile, then his brother must be even more "varied and competent" that Bill, The sentence therefore offers an example of a comparison clue provided by the writer.

Unlike his brother, who was friendly with everyone, Bon was quite surly.
The clue: The sentence is an example of a contrast clue because Bob is described as being surly. The word "unlike" shows that Bob is different from his brother and his brother is friendly with everyone, so surly must mean the opposite of "friendly" and therefore means: bad-tempered or unfriendly. [R13]

\section{G. Word Structure [R14]}

The morphemic structure of words especially compounds and derives words offers clues for inferring the meanings of unknown words.

\section{Example:}

\section{COPERNICUS BELIEVED IN A HELIOCENTRIC UNIVERSE, RATHER THAN IN THE GEOCENTRIC THEORY}

If we know the form geo- as in geology or geography as well as the feat that it is used in contrast to helio-, we should not have much difficulty in guessing the meanings of heliocentric and geocentric with the help of our historical knowledge of Copernicus contribution.

The above context clues are important ways to help readers master the new words and improve reading skills. As we all know, reading is an active process, during which the readers may think over. If readers can master the skills of guessing words and using context clues, they can be better readers than before.

Besides all the methods mentioned above, it is imperative to know some differences in vocabulary and meaning between British English and American English .[R15]

Due to the differences in the population structure, physical environment, social and economic conditions, American English has diverged somewhat from British English. Most vocabulary in American English and British English has the same meaning. Few words reflect the differences in vocabulary and meaning.

Some vocabulary developed individually in the two languages. This phenomenon make the words lost their basic meaning and gradually obtained some new meanings. This finally changed the meaning of the vocabulary in the two languages. Subway as the meaning of a passage under something gradually disappeared. In American English subway means the train under the ground, while it means pavement under the ground in British English. We must pay special attention on this kind of words. Other examples: billion, wash up, etc.

At the same time, there are words applied specifically only in one country in English. American English has its specific vocabulary to describe its special geography and animals. But these words are unfamiliar with British people. Let us take some words for example.

E.g. everglades caribou canyon bankroll interstate

There are also many words can only be used in British English.

E.g. wicket bowler prince duke marquis 


\section{CONCLUSIONS}

English is becoming more and more important in our daily life and expanding vocabulary, as well as improving reading skills are the basic abilities in learning English as a foreign language. Thus we reader should practice more reading and meanwhile try to master some efficient reading skills, guessing the meaning of words through word structure and context clues. Besides, mastering some differences in vocabulary and meaning between British English and American English is of great help in our reading and learning English.

\section{REFERENCES}

[1] [R1] Li Fangmu English Coaching Paper.

[2] [R2]; [R3]; [R4]; [R5];[R6];[R7];[R8];[R9] Zhang Weiyou English Lexicology Chapter4 Word Formation II P45 Foreign Language Teaching And Research Press, 1999.

[3] [R10] AudreyJ.Roth and Sue Kahn. College Reading Skills and Strategies NewYork St. Martin's Press.

[4] [R11]; [R14] Zhang Weiyou. English Lexicology Chapter8 Meaning and Context Foreign Language Teaching and Research Press, 1999.

[5] [R12] Luan Lan. Meaning Guessing Strategies in English Reading[J] Changchun University of Science and Technology, 2005,3.

[6] [R13] AudreyJ.Roth and Sue Kahn. College Reading Skills and Strategies New York St. Martin's Press.

[7] [R15] Dai weidong, He zhaoxiong. New Concise English Linguistics Course Shanghai Foreign Language Education Press, 2010. 